MINERALOGIA, 49, No 1-4: 7-16 (2018)

Original paper

\title{
Influence of liquid-nitrogen freezing of gas-bearing shale rocks on their compressive strength
}

\author{
Kinga Borek ${ }^{1 *}$ \\ ${ }^{1}$ Institute of Geological Sciences, Jagiellonian University, Gronostajowa 3a, 30-387 Krakow, Poland \\ * Corresponding author \\ e-mail: kinga.borek@student.uj.ed.pl
}

Received: November 7, 2017

Received in revised form: December 29, 2017

Accepted: January 20, 2018

Available online: March 15, 2018

\begin{abstract}
Any definable relation between falling temperature and the compressive strength of shale rocks should provide a useful predictive tool aiding optimization of the results of hydraulic fracturing. In this research, an automeasuring hydraulic press, a thermo-camera and the Fluent ANSYS software were used. The results of laboratory simulations, and the effects of experiments conducted on shale rocks to determine permanent changes in compressive strength, are presented. As both frozen rocks and rocks returned to room temperature show diminished compressive strength. It is suggested that prior freezing of rocks can increase the efficiency of fracturing.
\end{abstract}

Key-words: hydraulic fracturing, black shales, freezing, compressive strength, modelling

\section{Introduction}

\subsection{Shale gas exploitation}

Unconventional hydrocarbon resources are of increasing importance as both population growth and technical progress constantly drives an increasing demand for fossil energy resources. Shale gas is one feasible option. Thus, new gas- and oil bearing shale basins are being assessed. However, many of these prospects remain technically unrecoverable (U.S. Energy Information Administration 2017).

The extraction of shale gas or oil demands dedicated technology because of their specific mechanical properties, especially their low fragility. To be considered a potential 
gas resource, shale rock must fulfill many requirements pertaining to porosity, total organic carbon content (TOC), maturity, mineralogy, gas-in-place, permeability, kerogen type, etc. (Boyer et al. 2006; Jarvie et al. 2007). Even where these various requirements are met, the exploitation of shale gas compared requires hydraulic fracturing, not as a complementary technique as in the exploitation of conventional resources, but as a primary method. Shale rocks contain oil or gas captured in micro- or nano-scale pores. Therefore, to obtain an effective porosity enabling gas- or oil flow to a well, it is necessary to combine the pores with a crack mesh as dense as possible ( $\mathrm{Li}$ et al. 2015). The fracturing process involves the injection into the rock of a fluid under high pressure. The shales crack open, releasing contained gas or oil. Flowback water is recovered, enabling the collection of the gas or oil (Jarvie et al. 2007).

\subsection{Possibilities to improve the hydraulic fracturing process}

The hydraulic fracturing technology was invented in the 1950s and has been further developed ever since (King 2010). Apart from the process itself, the efficiency of the technique depends on many factors, especially the petrophysical properties of the rocks and their formation parameters (Cipolla et al. 2008). With the Polish Ordovician-Silurian gasbearing shales, the main difficulties are their depth and low susceptibility for fracturing. Since the first fracturings in Poland until the present, recovery factors have risen from $2 \%$ up to $50 \%$; this is still far from satisfying (Kasza 2013). All that has already been done to date has centered on the fracturing itself, namely, on the choice of the fracturing fluid, i.e., the choice of propant or on well stimulation. The research described here is based on different principle, namely, changing the shales, not the process.

The fact that the natural freezing process often results in changes in the physical parameters of materials led to questioning if the same would happen with gas bearing black shales. The freezing of shale samples, as here, was purely for making observations on the phenomenon - a necessary prelude to research on the applicability of such a method. Freezing is currently a popular technique in both geoengineering and civil engineering; freezing of water in soils is widely used to contain the water, facilitating later procedures. Recently, there has been an increasing interest in the applicability of freezing methods at greater depth; freezing of coal and shales has been conducted, with sandstone, concrete and marble used for comparison (Cai et al. 2014; Zhai et al. 2017).

\section{Samples and methods}

\subsection{Sampling site and preparation}

The experiment was based on shale samples from the Prągowiec Ravine near Bardo in the Holy Cross Mountains. The Pragowiec Ravine outcrop lies in an area of varying lithologies (Trela 2006). All nine samples (Fig. 1,2) were taken from the same core drilled perpendicular to the schistosity in upper Ordovician and lower Silurian units. 


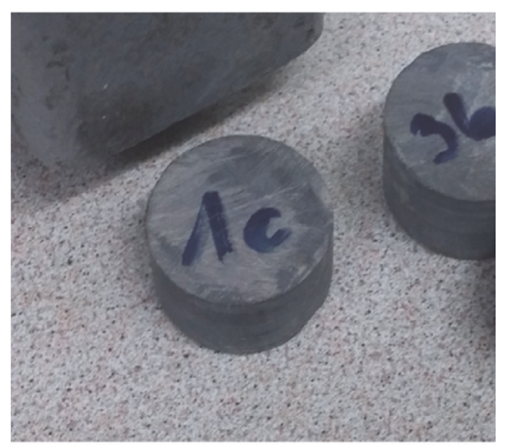

Fig. 1. Gas-bearing shale rock sample

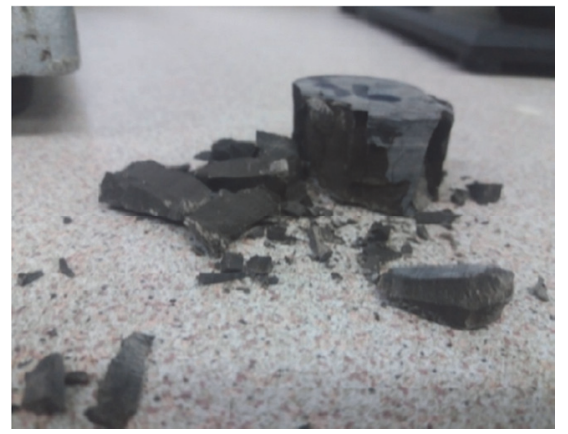

Fig. 2. Gas-bearing shale rock sample after test

Though the shale-rock samples used in the experiment were not analyzed as part of this research, shales from the very same outcrop have been described by the Polish Geological Institute. The samples are typical of the outcrop for which Mustafa et al. (2015) have provided details on petrological composition and kerogen content (Table 1).

TABLE 1

Mineral composition of black shale from Prągowiec Ravine and its kerogen content (Polish Geological Institute National Research Institute, 2013)

\begin{tabular}{llll}
\hline Component & Content [\%] & Component & Content [\%] \\
\hline Quartz & 54.1 & Kerogen & 3.4 \\
Clay minerals & 27.2 & Calcite & 2.3 \\
Pyrite & 5.1 & Dolomite and Ferroan-dolomite & 1.4 \\
Plagioclase & 5.1 & Potassium feldspar & 1.4 \\
\hline
\end{tabular}

TABLE 2

Samples data

\begin{tabular}{llllll}
\hline Sample & $\begin{array}{l}\text { Height } \\
(\text { circa* 0.1 cm) } \\
{[\mathrm{cm}]}\end{array}$ & $\begin{array}{l}\text { Weight } \\
(\text { circa*0.1g) } \\
{[\mathrm{g}]}\end{array}$ & $\begin{array}{l}\text { Top surface } \\
{\left[\mathrm{cm}^{2}\right]}\end{array}$ & $\begin{array}{l}\text { Volume } \\
{\left[\mathrm{cm}^{3}\right]}\end{array}$ & $\begin{array}{l}\text { Density } \\
{\left[\mathrm{kg}\left(\mathrm{m}^{3}\right)\right]}\end{array}$ \\
\hline S1; S2; S3 & 1.5 & 44.4 & & 17.1 & \\
L1; L2; L3 & 1.9 & 57.5 & 11.4 & 22.1 & 2599.7 \\
M1; M2; M3 & 2.1 & 63.4 & & 23.9 & \\
\hline
\end{tabular}

*circa represents maximum differences extent between samples weight and height.

The requirements for testing the samples with the hydraulic press were parallel top- and bottom surfaces. All the samples were cylinder shaped. Due to the limited number of 
samples, a method was elaborated to help maximize the reliability of the measurements. The nine samples of shale rock were divided into three groups (S, M and L) of different height (Table 2). In each group, one sample was tested at room temperature (S1, M1 and L1), one was tested directly after being frozen (S2, M2 and L2) and one after reequilibration with room temperature (S3, M3 and L3). All samples were stored at a typical laboratory temperature and humidity. Though rock is an inhomogenous matter, the tested shales are dense enough to make any difference in weight negligible.

\subsection{Course of the experiment}

For the experiment on the influence of freezing on the gas-bearing shales, a series of tests using a hydraulic press were conducted, during which the samples were crushed. To compare the behaviour of the samples at room temperature and after freezing, a freezing agent had to be chosen. Due to its availability, its specific parameters (mainly thermodynamical- and thermal properties, e.g. boiling point) and safety of use, its nontoxicity and non-reactivity (Higgins 2015), liquid nitrogen was an obvious choice.

\subsubsection{ANSYS heat flow modelling}

To make the experiment more consistent, heat flow modelling using Fluent ANSYS was undertaken. For the proper execution of the simulation, the size parameters of the largest samples (group L) were inserted in the software. The freezing process was first simulated using the finite element method (FEM) to predict possible results to choose the freezing method and to optimize the time of freezing. A tetrahedral mesh (Fig. 3) was placed on the image of the sample to create as many contact points as possible. (Alawadhi 2010). As the method requires great computing power, surrounding liquid with minimal flow was modeled (Fig. 4). With the relevance setting set to fine, and smoothing to high, the mesh created was optimal for the modeling process. The properties of liquid nitrogen were taken from the Fluent ANSYS software database and the properties of the shale rocks from former measurements and literature.

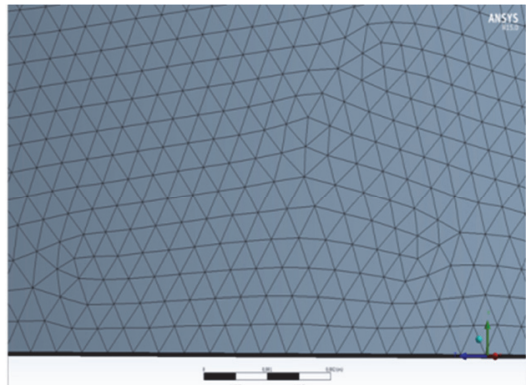

Fig. 3. View of designed mesh

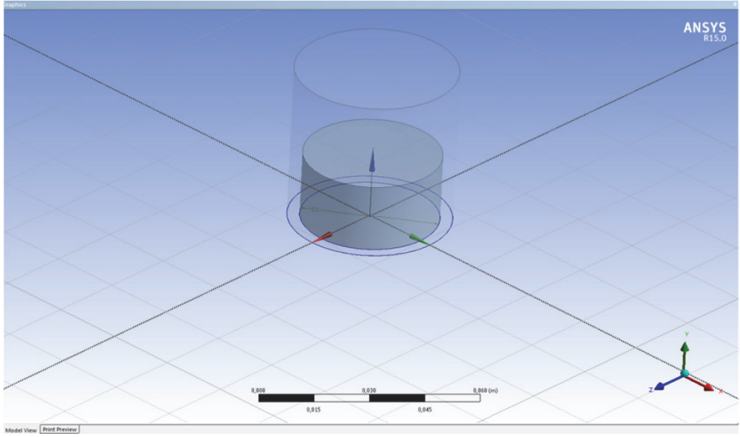

Fig. 4. The view of sample with surrounding liquid while modeling 


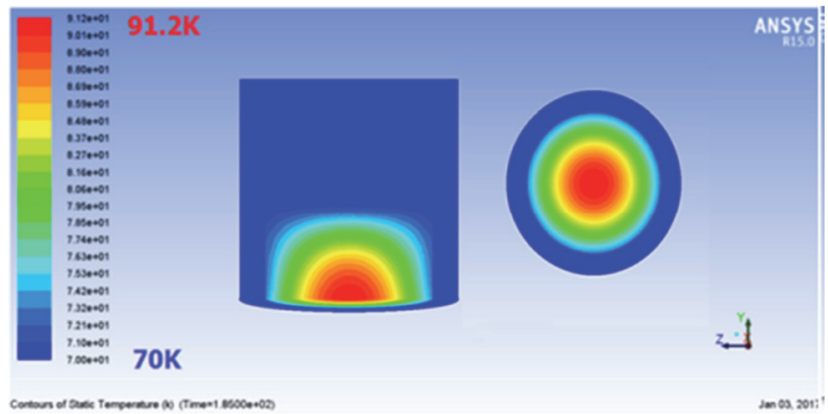

Fig. 5. Side and top views of sample after 180 seconds of freezing

After the simulation, the largest sample reached the lowest temperature after 180 seconds of freezing (Fig. 5).

\subsubsection{Freezing process and hydraulic press test}

Samples S1, M1 and L1 were placed in the hydraulic press without freezing. Samples S2, M2 and L2 were compressed while frozen. Finally, samples S3, M3 and L3 were first frozen and then left to return to ambient temperature before testing (Fig. 6). The temperature history was monitored using a thermo-camera.

With samples S2, M2 and L2 which were placed frozen in the press, the thermo-camera, due to its limited scope, indicated a temperature of at least $-40^{\circ} \mathrm{C}$ (Fig. 7). The model from the Fluent ANSYS software provided a precise result of $91.2 \mathrm{~K}$ which equals $-181.95^{\circ} \mathrm{C}$.

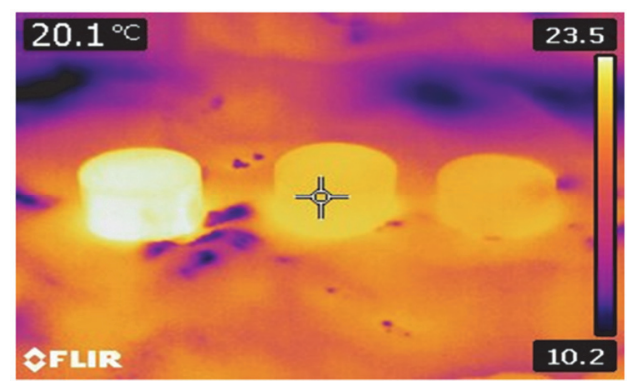

Fig. 6. Samples S3; M3; L3 returning to room temperature

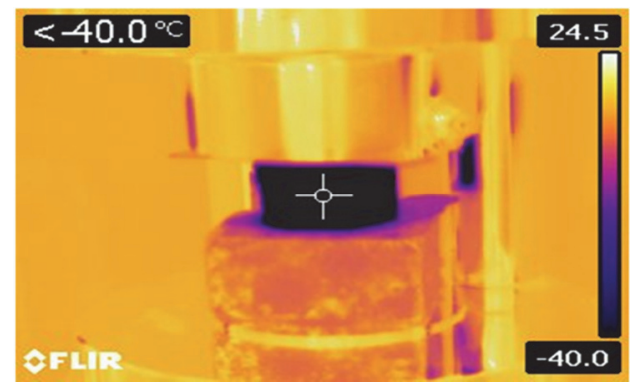

Fig. 7. Sample $\mathrm{S} 2$ during crushing

\section{Results}

\subsection{Compressive strength factor}

The compressive strength factor was computed based on the critical applied load measured by the hydraulic press: 


$$
R c=\frac{P c}{A}
$$

$R c$ - compressive strength factor; $P c$ - critical applied load; $A$ - area of applied pressure.

\subsection{Measured compressive strength factor $(R c)$ and its correlation with temperature}

The plotted results (Fig. 8, 9, 10) clearly indicate that, in all cases, values of the compressive strength factor are highest for the samples tested at in room temperature (S1, M1 and L1), intermediate for those that were frozen (S2, M2 and L2) and lowest for those that had been frozen and returned to room temperature (S3, M3 and L3). The sample freezing is the crucial variable.

By comparing the Rc factors and temperatures of the samples, it is evident that that the difference comes from previous freezing, as is shown in Figures 11, 12 and 13, where number 1 stands for room temperature sample, number 2 for a frozen one, and number 3 is the one frozen re-equilibrated to room temperature). No connection between sample heights and $\mathrm{Rc}$ values was observed.

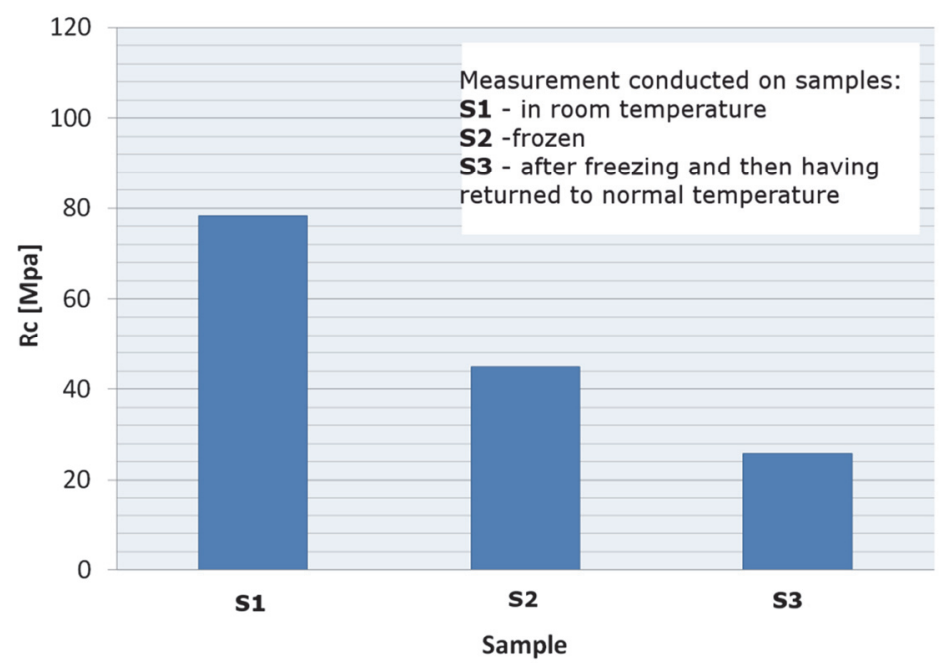

Fig. 8. Compressive strength factor for samples of group "S" 


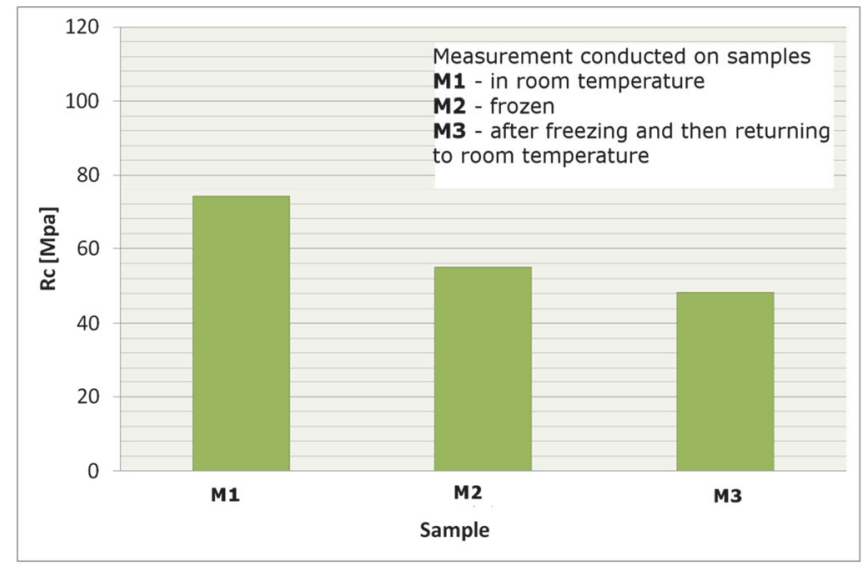

Fig. 9. Compressive strength factor for samples of group " $M$ "

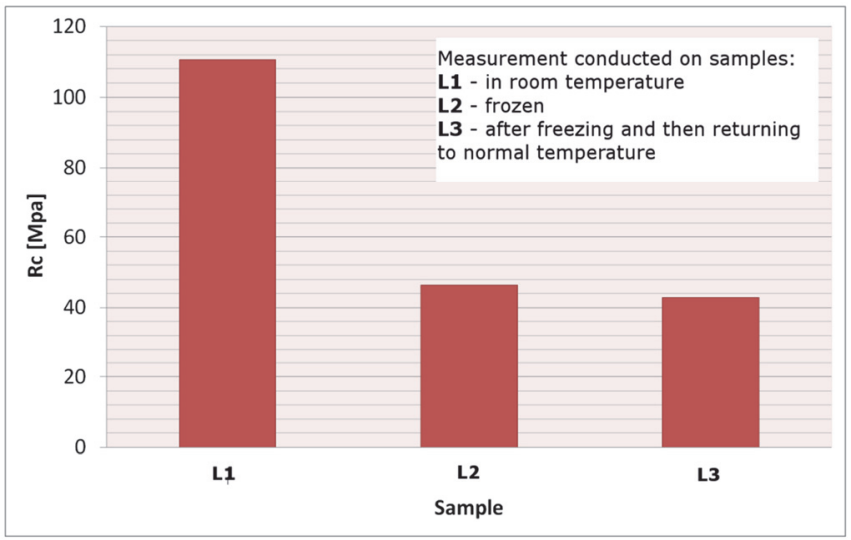

Fig. 10. Compressive strength factor for samples of group "L"

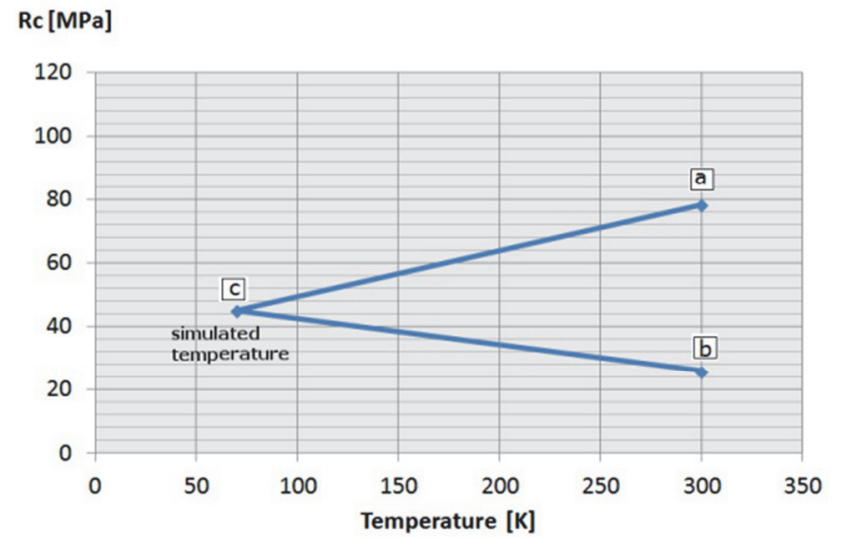

Fig. 11. Compressive strength factor change in correlation with temperature for samples of group "S" 


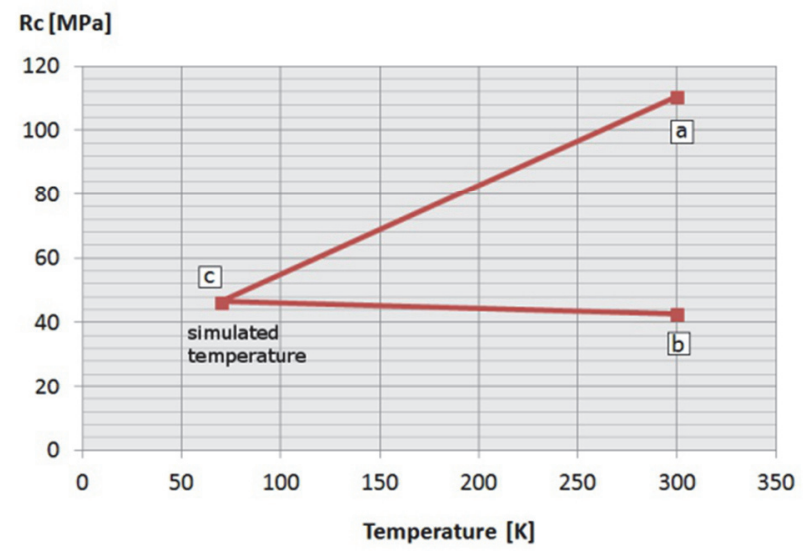

Fig. 12. Compressive strength factor change in correlation with temperature for samples of group "M"

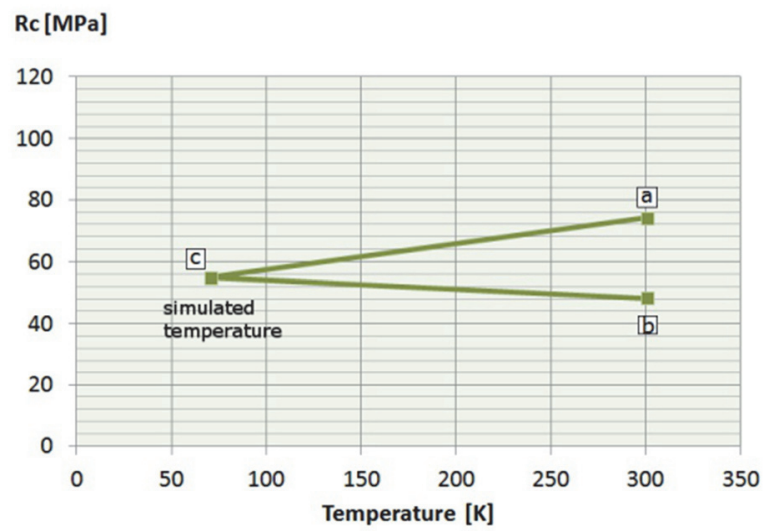

Fig. 13. Compressive strength factor change in correlation with temperature for samples of group "L"

\section{Discussion}

The experiment described above indicates that lowered temperatures change the compressive strength of the tested shales. It might be speculated that the lower the temperature, the lower the compressive strength. However, it may be more complex than that; the experiment shows that shale samples re-equilibrated to room temperature after freezing show the lowest compressive strength of all.

Freeze-thaw cycles has been lately discussed in terms of changing physical parameters of coal (Zhai et al. 2017). Nano- and micropores were found to diminish in amount with each cycle, as numbers of mesopores and regular-sized cracks simultaneously increased. Such an observation might allow the conclusion that the greater number of pores and cracks would account for any greater fragility. That might be the case with the shale rocks studied 
here, but no data is available. Research has been carried out concerning humidity and temperature in relation to changes in the properties of multiple rocks, including shale rock (Cai et al. 2014); SEM studies showed the development of significant cracking and of pores in response to temperature change. Thus, it may be that it is the increase in effective porosity (no cracks were noted) after freezing and thawing that is responsible for the diminished compressive strength values demonstrated in the Pragowiec Ravine shales.

Recently, studies have been conducted on shale rocks heated to a range of temperatures between $20-400^{\circ} \mathrm{C}$ (Rybacki et al. 2015). On testing, the heated samples displayed diminished values of compressive strength. However, differences observed also reflected factors such as origin, porosity, etc. In that study, the samples were not tested after returning to room temperature. Nevertheless, changes in temperature, up or down, do result in changes in compressive strength of shales.

The key influencing process is expansion due to heating and/or freezing. The rock microstructure is also modified by the compaction and decompaction processes related to changes in temperature. The influence of changing temperature on a rock need not be an isotropic process; it is dependent on the direction of the changes and nonlinear samedirection dependences will likely appear (Huotari, Kukkonen 2004). The degree of thermal expansion varies for each component in a shale rock. Moreover, the distinctive components with differing thermal qualities influence each other. What happens when the temperature of a rock changes is clearly, in detail, very complex. Even in the simple experiment described here, the temperature changes in opposite ways as the rock is firstly frozen and then heated as it returns to room temperature. The fact that both freezing and heating result in similar effects raises questions as to why.

\section{Conclusions}

The results of the freezing experiment and the software modeling show that freezing diminishes the compressive strength of gas-bearing shale rocks. Liquid nitrogen proved to be an effective freezing agent. The parameters of shale rock are changed not only when it is in the frozen state, but when it returns to room temperature. It is suggested that the prior freezing of rocks can increase the efficiency of hydraulic fracturing.

Acknowledgements. The research was mainly conducted as a part of a thesis completed in the faculty of Drilling Oil and Gas of AGH University of Science and Technology in Krakow under the supervision of dr hab. inż. Jan Ziaja.

\section{References}

Alawadhi, E. M. (2010). Finite Element Simulations Using ANSYS. Florida. CRC Press. ISBN 978-1-4398-016-1 Boyer, C., Kieschnick, J., Suarez-Rivera, R., Lewis, R.E., \& Waters, G. (2006). Producing Gas from its source. Oilfield Review, 18, 36-49.

Cai, Ch., Li, G., Huang, Z., Shen, Z., Tian, S., Wei, J. (2014). Experimental study of the effect of liquid nitrogen cooling on rock pore structure. Journal of Natural Gas Science and Engineering, 21, 507-517. DOI: https://doi.org/10.1016/j.jngse.2014.08.026

Cipolla, C. L., Warpinski, N. R., Mayerhofer, M. J., Lolon, E. P., \& Vincent, M. C. (2008). The relationship between fracture complexity, reservoir treatment and fracturing treatment design. SPE 2008. 115769. DOI: https://doi.org/10.2118/115769-MS. 
Higgins, E. W. (2015). Liquid Nitrogen: Characteristics, Uses and Safety concerns. New York. Nova Science Publishers, Incorporated. ISBN 978-1-63483-803-0

Huotari, T., \& Kukkonen I. (2004). Thermal Expansion Properties of Rocks: Literature Survey and Estimation of Thermal Expansion Coefficient for Olkiluoto Mica Gneiss. Geological Survey of Finland. Posiva 2004-04

Jarvie, D. M., Hill, R. J., Ruble, T. E., Pollastro, R. M. (2007). Unconventional shale-gas systems: the Mississippian Barnett shale of north-central Texas as one model for thermogenic shale-gas assessment. American Association of Petroleum Geologists Bulletin 91, 475-499. DOI: https://doi.org/10.1306/ 12190606068 .

King, G. E. (2010) Thirty years of gas shale fracturing: What we have learned. SPE 2010. 133456.

Kasza, P. (2013). Efektywne szczelinowanie łupków w Polsce. Nafta-Gaz, 11, 807-813. (in Polish).

Li, Q., Xing, H., Liu, J., \& Liu, X. (2015). A review of hydraulic fracturing of unconventional reservoir. Petroleum, 1, 1, 8-15. DOI: https://doi.org/10.1016/j.petlm.2015.03.008.

Mustafa, K. A., Sephton, M., Watson, J. S., Spathopoulos, F., \& Krzywiec, P. (2015). Organic geochemical characteristics of black shales across the Ordovician-Silurian boundary in the Holy Cross Mountains, central Poland. Marine and Petroleum Geology, 66, 1042-1055. DOI: https://doi.org/10.1016/j.marpetgeo. 2015.08.018.

Polish Geological Institute National Research Institute. (2013). Państwowa służba geologiczna o gazie w łupkach. ISBN 978-83-7863-266-5

Rybacki, E., Meier, T., \& Dresen, G. (2015). What controls the mechanical properties of shale rocks? - Part I: Strength and Young's modulus. Journal of Petroleum Science and Engineering, 135, 702-722. DOI: https://doi.org/10.1016/j.petrol.2015.10.028.

Trela, W. (2006). Lithostratigraphy of the Ordovician in the Holy Cross Mountains. Przegląd Geologiczny. 55, 622-631. (in Polish with English summary).

U.S. Energy Information Administration (2015, September) Map of basins with assessed shale oil and shale gas formations. Retrieved October 7, 2017, from https:/www.eia.gov/analysis/studies/worldshalegas/.

Zhai, Ch., Wu, S., Liu, S., Qin, L., \& Xu, J. (2017). Experimental study on coal pore structure deterioration under freeze-thaw cycles. Environmental Earth Sciences, 76, 507. DOI: https://doi.org/10.1007/s1266. 